\title{
Drought Occurrence Probability Analysis Using Multivariate Standardized Drought Index and Copula Function Under Climate Change
}

Kimia Naderi

Arak University

mahnoosh moghaddasi ( $\square$ mah_moghaddasi@hotmail.com )

Arak University

Ashkan Shokri

Australian Bureau of Meteorology

\section{Research Article}

Keywords: Climate change, Copula function, MSDI, SSP, Drought, Iran

Posted Date: November 22nd, 2021

DOl: https://doi.org/10.21203/rs.3.rs-927927/v1

License: (c) (i) This work is licensed under a Creative Commons Attribution 4.0 International License.

Read Full License 


\title{
Drought Occurrence Probability Analysis Using Multivariate Standardized Drought Index and Copula Function Under Climate Change
}

\author{
Kimia Naderi ${ }^{1}$, Mahnoosh Moghaddasi ${ }^{2,3}$, Ashkan shokri $^{4}$ \\ ${ }^{1}$ Department of Water Science and Engineering, Faculty of Agriculture and Environment, \\ Arak University, Arak, Iran. \\ $2^{*}$ Department of Water Science and Engineering, Faculty of Agriculture and Environment, \\ Arak University, Arak, Iran. (Corresponding author: mah_moghaddasi @ hotmail.com) \\ ${ }^{3}$ Department of Water Resources, Water Institute, Arak University, Arak, Iran. \\ ${ }^{4}$ Bureau of Meteorology, Melbourne, Australia
}

\begin{abstract}
This study aims to investigate the effect of climate change on the probability of drought occurrence in central Iran. To this end, a new drought index called Multivariate Standardized Drought Index (MSDI) was developed, which is composed of the Standardized Precipitation Evapotranspiration Index (SPEI) and the Standardized Soil Moisture Index (SSI). The required data included precipitation, temperature (from CRU TS), and soil moisture (from the ESA CCA SM product) on a monthly time scale for the 1980-2016 period. Moreover, future climate data were downloaded from CMIP6 models under the latest SSPs-RCPs emission scenarios (SSP1-2.6 and SSP5-8.5) for the 2020-2056 period. Based on the NRMSE, $\mathrm{S}_{\mathrm{n}}$, and NS evaluation criteria, the Galambos and Clayton functions were selected to derive copula-based joint distribution functions in both periods. The results showed that more severe droughts and longer will occur in the future compared to the historical period and in particular under the SSP5-8.5 scenario. From the derived joint return period, a drought event with defined severity or duration will happen in a shorter return period as compared with the historical period. In other words, joint return period indicated a higher probability of drought occurrence in the future period. Moreover, the joint
\end{abstract}


return period analysis revealed that the return period of mild droughts will remain the same, while it decresed over extreme droughts in the future.

Keywords: Climate change, Copula function, MSDI, SSP, Drought, Iran

\section{Introduction}

Drought as a recurring natural hazard can affect water resources such as water supply, surface and subsurface water availability, and management of water resources (Van loon et al., 2014; Amin et al., 2016; FAO, 2017; Scanlon et al., 2017; Hameed et al., 2020). Droughts are broadly categorized into meteorological (Hameed et al., 2018), hydrological (Barker et al., 2016), agricultural (Yan et al., 2017), or socio-economical droughts (Huang et al., 2016). It is a threedimensional, complex natural hazard characterized by severity (magnitude or intensity), duration, and areal extent (Tsakiris et al., 2007; Wilhite et al., 2014; Van Loon, 2015; Deo and Sahin, 2015; Deo et al., 2017; Mohammed \& Scholz, 2017), which has been studied from the environmental or the water resource point of view (Wilhite \& Glantz, 1985). The independence of drought characteristics makes the drought-related problems very complex and hard to deal with (Mishra \& Singh, 2010). Several studies about drought risk analysis at higher dimensions have been conducted to investigate the interrelation between drought characteristics (Ma et al., 2013; Hang et al., 2015). Copula function has been frequently employed in such multidimensional drought risk analyses with promising results (Zhang et al., 2020; Das et al., 2020; Bazrafshan et al., 2020; Sajeev et al., 2021).

Several indices are defined to quantify the drought severity, duration, and other characteristics (Afshar et al., 2020). Among them, Standardized Precipitation Index (SPI; McKee et al., 1993) and Standardized Precipitation Evapotranspiration Index (SPEI; Vicente-Serrano et al., 2012) are 
the most used indicators for analyzing the severity, duration, and frequency of meteorological drought (Svoboda \& Fuchs, 2016). SPEI uses precipitation and temperature to identify drought periods and their severity (Dubrovsky et al., 2008). Therefore, due to using temperature as an input, it can assess the effect of climate change more accurately compared to SPI (VicenteSerrano et al., 2010a). For agricultural drought, many indices have been developed such as the Empirical Standard SM Index (ESSMI; Carrao et al., 2016), Standard Soil moisture Index (SSI, Hao \& Aghakouchak, 2013; Aghakouchak, 2014), SM Percentile (SMP; Aghakouchak et al., 2015), and Soil moisture-based Drought Severity Index (DSI; Cammalleri et al., 2016). Among these indices, SSI is used more frequently as its calculation process is similar to other standardized drought indices (e.g. SPI and SPEI) and is based on the anomalies in long-term data (Zhang et al., 2019).

Recently, efforts have been made to develop multivariate indices based on a combination of different drought indices to provide insight into the conditions and characteristics of this climatic event (Beersma \& Buishand, 2005; Hao \& AghaKouchak, 2014; Li et al. 2015). Various methods and theories have been developed to quantify multivariate indices, including copula functions (Nelsen, 2006; Salvadori \& Michele, 2007; Hao \& AghaKouchak, 2014; Hao et al. 2014; Vergni et al., 2015; Mortuza et al., 2019; Tahroudi et al., 2020), scalogram model (Sough \& Mosaedi, 2013; Sough et al., 2018), principal component analysis (PCA) (Keyantash \& Dracup, 2004; Rajsekhar et al., 2014; Fahimirad \& Shakarmai, 2021), entropy theory (Waseem et al., 2015), and Markov chain method (Rezaeianzadeh et al., 2016).

Based on several studies on climate change model analysis, Earth has been getting warmer in recent years (Solomon et al., 2007). This is expected to lead to an increase in the occurrence of drought (Sheffield \& Wood, 2008). In recent years, many studies have reported that climate change impacts water resources, environment, health, and safety to a great extent (Tirado et al., 
2010; Danandeh Mehr \& Kahya, 2017; Khajeh et al., 2017; Thilakarathne et al., 2017). Many studies have used the copula function method to statistically analyze drought under climate change conditions (Mesbahzadeh et al., 2020; Afshar et al., 2020).

In this research, a new multivariate standardized drought index (MSDI) is proposed to combine agricultural and meteorological drought indices (SPEI and SSI) in historical and future periods in central Iran. These indices were incorporated through the Entropy Weighting (EW) method and the needed data were extracted from CRU TS and ESA CCI SM products and three CMIP6 models under the SSP1-2.6 and SSP5-8.5 scenarios, respectively. Bivariate copula functions were used for joint modeling of droughts based on MSDI. Using the joint probabilities derived from the copula functions, the bivariate drought return period was calculated based on its characteristics to investigate the future drought changes in comparison with the historical period. Moreover, the impact of climate change on mild and extreme drought was examined. What set this study apart from prior works included (1) selecting indices based on the best indicator for characterizing drought conditions in a region and (2) developing a new index based on two indices to monitor agricultural and meteorological drought.

\section{MATERIAL AND METHODS}

\subsection{Study area and evaluation datasets}

Markazi province is located in central Iran and is known as the industrial capital of Iran. Its climate is warm and dry, with very low rainfall. It has an average annual rainfall and temperature of $261 \mathrm{~mm}$ and $14.6^{\circ} \mathrm{C}$. The most important and largest plain in the province is the Arak plain (Miqan desert), which hosts enormous industrial and agricultural facilities. The extent of this basin is $5460 \mathrm{~km}^{2}, 3100 \mathrm{~km}^{2}$ of which is flat and the rest is mountain-outs. Miqan wetland is one of the 10 major wetlands in Iran and is located in the center of the study area (Figure1). 
Groundwater is the most important natural resource to supply water demands. Recently, numerous factors such as population growth, agriculture development, climate variability, and over-extraction have led to declining groundwater levels in this plain.

Figure 1. The Case Study

\subsection{Datasets}

The following datasets were used in this research work:

- $\quad$ Station-based observations

The validation of the projected data was performed using monthly temperature and precipitation records obtained from Iran's Ministry of Energy for the selected station from 1980 to 2016.

- Climate Research Unit (CRU)

CRU produced time series of monthly climate variables from 1901 to 2016 with a 0.5-degree spatial resolution (New et al., 1999; Mitchell \& Jones, 2005). Monthly gridded data were generated from monthly ground-based climate variables over land. These data were interpolated using Inverse Distance Weighted (IDW). This dataset was compared with observational pointbased data measured in Arak synoptic station for validation (Table 1). As can be seen, statistical criteria revealed that the accuracy of CRU data is reliable. Therefore, monthly precipitation and temperature were sourced from this dataset (https://data.ceda.ac.uk).

Table 1.

- Satellite Soil Moisture products

The satellite SM product originates from ESA CCI (https://www.esa-soilmoisture-cci.org/). The product consists of three surface SM datasets. "ACTIVE Product and PASSIVE Product", 
which were created by fusing scatterometer and radiometer soil moisture products, respectively. The "COMBINED Product" is a blended product based on the former two datasets. The product provides global surface SM from 1978 to 2018 at a spatial resolution of $0.25^{\circ}$ and a temporal resolution of 1 day (Liu et al., 2011; Liu et al., 2012; Wagner et al., 2012; Dorigo et al., 2015). It should be noted that there is no gauge against which this dataset can be validated in this area. A study by Rahmani Kam (2015) confirmed the accuracy of ESA CCI data throughout Iran. Still, to ensure their reliability, the variation trend of soil moisture was compared with (1) climate variables including precipitation and temperature and (2) the distribution of operational wells. For example, Figure 2(a) shows the changes in monthly mean temperature, precipitation, and soil moisture in Arak station. As can be observed, the changing trend of soil moisture corresponds to temperature and precipitation. Moreover, the lowest and highest soil moisture figures were extracted from the Gavar and Sarugh station, which correspond to the distribution of wells (Figure2, b).

\section{Figure 2.}

- Future Soil Moisture and Climate Data

The CMIP6 climate model outputs were downloaded from https://esgfnode.llnl.gov/search/cmip6/. Scenarios of IPCC's sixth assessment report investigate climate change using a combination of RCPs and SSPs scenarios (Eyring et al., 2016). The 1980-2016 period of historical simulation covers the temperature observation period and is appropriate for comparison with the observed records. The four available CMIP6 models were investigated to project climate variables under two future SSP scenarios, namely SSP1-2.6 as a low forcing scenario (sustainable development) and SSP5-8.5 as a strong forcing scenario (fossil-fueled development). Detailed information on these models is listed in Table 2. It should be noted that 
the future soil moisture was obtained based on the future precipitation and temperature using multiple linear regression in TableCurve 3D.

Table 2.

\subsection{Methodology}

An overview of the methodology of the current research is as follows (Figure 3):

Figure 3.

As iullstrated in this flowchart, the required data were extracted from the CRU dataset, ESACCI SM products, and AR6 models. Different indices and Run Theory were used to calculate the severity and the duration of drought, while evaluation criteria were applied to choose the best distribution through these characteristics. The best bivariate distribution function for the severity and duration of the drought was then chosen through three steps. First, measuring the correlation between the Spearman coefficient and Tau Kendall. Second, calculating the parameter of copula functions based on the IFM $^{1}$ method (Joe, 1997). Third, evaluating the copula cumulative distribution functions and experimental copula functions based on the evaluation criteria. Then, joint probability and joint return periods were calculated. This process was conducted for historical and projected future periods under SSP1-2.6 and SSP5-8.5 scenarios.

\subsubsection{Standardized Precipitation Evapotranspiration Index (SPEI)}

This index is based on a monthly climate water balance, which is the difference between precipitation and Potential EvapoTranspiration (PET) and is obtained as standard values of the probability distribution function of the deficit or surplus accumulation of a climate water balance at different time scales (McKee et al., 1993; McKee et al., 1995). PET is calculated using the Thornthwaite equation (Thornthwaite, 1948), which is a function of monthly mean temperature.

\footnotetext{
${ }^{1}$ Inference Function for Margins
} 
The difference between precipitation $(\mathrm{P})$ and potential evapotranspiration (PET) for the month $\mathrm{i}$ is calculated as follows:

$\mathrm{D}_{\mathrm{i}}=\mathrm{P}_{\mathrm{i}}-\mathrm{PET}_{\mathrm{i}}$

where $\mathrm{D}$ values are calculated according to the following relation in different time scales:

$$
\mathrm{D}_{\mathrm{n}}^{\mathrm{k}}=\sum_{\mathrm{n}=0}^{\mathrm{k}-1} \mathrm{P}_{\mathrm{n}-1}-\mathrm{PET}_{\mathrm{n}-\mathrm{i}}
$$

Where $\mathrm{k}$ (months) is the considered time scale and $\mathrm{n}$ is the considered month in the calculation. SPEI is calculated based on the 3-parameter log-logistic distribution. Parameters of the log-logistic distribution can be estimated following the L-moment procedure (Ahmad et al., 1988). The probability distribution function of the D series according to the log-logistic distribution is given by:

$$
\mathrm{F}(\mathrm{x})=\left[1+\left(\frac{\alpha}{\mathrm{x}-\gamma}\right)\right]^{-1}
$$

Where $\alpha, \beta$, and $\gamma$ are scale, shape, and location parameters, respectively for $\mathrm{D}$ values in the range $(\gamma<x<\infty)$. SPEI values are categorized into dry, wet, and normal periods (Table 2).

\subsubsection{Standardized Soil Moisture Index (SSI)}

SSI can be calculated similarly to SPI (Aghakouchak, 2014; Aghakouchak et al., 2015). This index is based on the SM content alone, reflecting the SM deficit compared to the long-term normal conditions. SSI is estimated by fitting the best probability distribution function to the historical SM records. In this area, the monthly SM follows the normal distribution. These are, then, transformed into standard values (mean $=0$, and variance $=1$ ) and SSI is calculated through the following equation: 


$$
S S I(i)=\frac{S M(i)-\overline{S M(l)}}{S M(i)(s t d)}
$$

where $\overline{S M}$ is the average soil moisture in the month (i) and $S M(s t d)$ is the standard deviation of soil moisture. The standardized soil moisture index values were classified as shown in Table 3.

\subsubsection{Multivariate Standardized Drought Index}

Entropy weighting is a method for weighting indices. First, the matrix derived from the indices is standardized. The next step is to calculate the entropy of each index according to the following equation:

$$
H_{j}=\frac{-1 \sum_{i=1}^{m} f_{i, j} \ln _{i, j}}{\operatorname{Ln}(m)}
$$

Wherein:

$r_{i, j}=\frac{-r_{i, j}}{\sum_{i=1}^{m} r_{i, j}}$

where $r_{i, j}$ is the index matrix value. Finally, the weight of each indicator is calculated according to the equation below ( $\mathrm{Li}$ et al., 2011):

$$
\begin{aligned}
& D_{j}=1-H_{j} \\
& w_{j}=\frac{D_{j}}{n-\sum_{j=1}^{n} H_{j}}
\end{aligned}
$$

where $w_{j}$ is the weight assigned to the variables, satisfying $\sum_{j=1}^{n} w_{j}=1$ and $D_{j}$ is a measure of the entropy among the $\mathrm{j}^{\text {th }}$ variable. The Multivariate Standardized Drought Index is proposed based on the entropy weighting method and its equation is as follows:

$$
M S D I=W_{S P E I} * S P E I+W_{S S I} * S S I
$$

$W_{\text {index }}$ is the weight of each index in the new index. 
Table 3.

\subsubsection{Copula function}

Sklar (1959) introduced the copula and described how univariate distribution functions can be combined into a multivariate distributions function. For $\mathrm{N}$-dimension continuous random variables $\left\{X_{1}, X_{2}, \ldots, X_{N}\right\}$ with $F_{\left(X_{i}\right)}=P_{x_{i}}\left(X_{i} \leq x_{i}\right)$ marginal distribution, the joint distribution of variable $\mathrm{X}$ is defined as follows:

$$
H_{X_{1}, \ldots, X_{N}}\left(x_{1}, x_{2}, \ldots, x_{N}\right)=P\left[X_{1} \leq x_{1}, X_{2} \leq x_{2}, \ldots, X_{N} \leq x_{N}\right]
$$

A copula is a function that connects univariate marginal distribution functions to form a bivariate or multivariate function. Sklar showed that the probabilistic multivariate distribution $\mathrm{H}$ can be defined with copula function $\mathrm{C}$ by using marginal distribution and affiliation structure:

$$
\mathrm{C}\left(\mathrm{F}_{\mathrm{X}_{1}}\left(\mathrm{x}_{1}\right), \mathrm{F}_{\mathrm{X}_{2}}\left(\mathrm{x}_{2}\right), \ldots, \mathrm{F}_{\mathrm{X}_{\mathrm{N}}}\left(\mathrm{x}_{\mathrm{N}}\right)\right)=\mathrm{H}_{\mathrm{X}_{1}, \ldots, \mathrm{X}_{\mathrm{N}}}\left(\mathrm{x}_{1}, \mathrm{x}_{2}, \ldots, \mathrm{x}_{\mathrm{N}}\right)
$$

Copula functions are divided into several families, among which, Archimedean joint functions are one of the most widely used functions in multivariate analysis of hydrological events (Nelsen, 2006). According to Table 4, five different copula functions were used in this research for drought multivariate analysis.

The parameter of the copula functions was needed to fit these functions to the duration and severity of drought. In this study, the IFM method was used for estimating the copula dependency parameters. This method includes two steps: first, different distributions were fitted through the severity and duration data and the best distribution was chosen based on NS and NRMSE statistics. Second, by implementing the parameters of the marginal distributions to the maximum log-likelihood function, this function was maximized to obtain the copula dependency parameter $(\theta)$. Then, the copula maximum likelihood algorithm function was maximized to 
obtain the copula dependence parameter. The results of each copula were compared against the results of experimental probability to choose the best-fitted copula.

\section{Table 4.}

Criteria such as normalized root mean square error (NRMSE), Cramer-von mises statistic $\left(\mathrm{S}_{n}\right)$ and the Nash Sutcliffe (NS) were used in this study, as presented below:

$$
\begin{aligned}
& \text { NRMSE }=100 \times \frac{\sqrt{\frac{\sum_{\mathrm{i}=1}^{\mathrm{N}}\left(\mathrm{C}_{\mathrm{pi}}-\mathrm{C}_{\mathrm{ei}}\right)^{2}}{N}}}{\mathrm{C}_{\mathrm{emax}}-\mathrm{C}_{\mathrm{emin}}} \\
& \mathrm{S}_{n}=\sum_{\mathrm{i}=1}^{\mathrm{N}}\left(\mathrm{C}_{\mathrm{pi}}-\mathrm{C}_{\mathrm{ei}}\right)^{2} \\
& N S=1-\frac{\sum_{\mathrm{i}=1}^{\mathrm{N}}\left(\mathrm{C}_{\mathrm{pi}}-\mathrm{C}_{\mathrm{ei}}\right)^{2}}{\sum_{\mathrm{i}=1}^{\mathrm{N}}\left(\mathrm{C}_{\mathrm{ei}}-\overline{C_{e}}\right)^{2}}
\end{aligned}
$$

Where $\mathrm{N}$ is the sample size, $\mathrm{C}_{\mathrm{p}}$ is the calculated value of the theoretical copula, $\mathrm{C}_{\mathrm{e}}$ is the observed values, and $\overline{\mathrm{C}_{\mathrm{e}}}$ is the mean of observed values.

\subsubsection{Bivariate Return Period}

Two modes of drought joint return period exist: i) return period for duration and severity values provided that both of them are more than the specific values, ii) return period provided that duration or severity of drought is more than the specific values so that they are respectively identified as $T_{D S}$ and $T_{D S}$ (Kendall \& Dracup, 1992; Mathier et al., 1992; Shiau, 2006).

$$
\begin{aligned}
& T_{D S}=\frac{E(L)}{P(D \geq d, S \geq S)}=\frac{E(L)}{1-F_{D}(d)-F_{S}(s)+C\left(F_{D}(d), F_{S}(s)\right)} \\
& \dot{T}_{D S}=\frac{E(L)}{P(D \geq d \text { or } S \geq S)}=\frac{E(L)}{1-C\left(F_{D}(d), F_{S}(s)\right)} \\
& E(L)=\frac{1}{\left(P_{0} * P_{1}\right)}
\end{aligned}
$$


Where $E(L)$ is the average interval time between the drought event, $F_{D}(d)$ and $F_{S}(s)$ are the cumulative distribution functions of duration and severity, $C\left(F_{D}(d), F_{S}(s)\right)$ is the joint cumulative distribution function of the drought severity and duration, and $\mathrm{p}_{1}$ and $\mathrm{p}_{0}$ indicate the occurrence and non-occurrence probability of drought.

\subsubsection{Downscaling}

The Change Factor (CF) method was implemented to downscale the GCM outputs and generate precipitation and temperature series for future periods. In the CF method, typically monthly ratios are generated for the historical series and climate change scenarios for temperature and precipitation. For constructing the climate change scenario of each GCM, the 'difference' and 'ratio' for the temperature and precipitation (equations 18 and 19), respectively, are calculated based on the long-term monthly average of the future period and historical period simulated by the same GCM model in each cell of computational grid (IPCC-TGCIA, 2007).

$$
\begin{aligned}
& P=P_{o b s} *\left(\overline{\frac{\bar{P}_{G C M, f u t, l}}{P_{G C M, b a s e, l}}}\right) \\
& \mathrm{T}=\mathrm{T}_{o b s}+\left(\overline{\mathrm{T}_{G C M, f u t, l}}-\overline{\mathrm{T}_{G C M, b a s e, l}}\right)
\end{aligned}
$$

where $\mathrm{P}_{\mathrm{obs}}$ and $\mathrm{T}_{\mathrm{obs}}$ indicate the observed precipitation and temperature time series in the

historical (baseline) period, $\overline{\mathrm{P}_{\mathrm{GCM}, \text { fut,1 }}}$ and $\overline{\mathrm{T}_{\mathrm{GCM}, \text { fut, } 1}}$ are the average time series of future

precipitation and temperature, and $\overline{\mathrm{P}_{\mathrm{GCM}, \text { base, } 1}}$ and $\overline{\mathrm{T}_{\mathrm{GCM}, \mathrm{base}, 1}}$ are the average time series of historical (baseline) precipitation and temperature.

\section{Results and Discussion}

\subsection{Impact of the lengths of record on meteorological drought}

In order to incorporate two indices, both of them should cover the same period. Since the soil moisture data were available for 37 years for calculating the agricultural index, the 
meteorological index was also calculated for the same period. For this purpose, the sensitivity of SPEI to the temporal length of data was analyzed as a contingency tables (Table 5). The match and non-match cases were determined as follows. If one class of drought occurrence, derived from the long-term record (100-year), matches the short-term record (37-year), it is called a "match", otherwise, it is called a "non-match". The results show that by increasing the SPEI time-scale $(1,3,6,9$, and 12$)$, the percentage of non-match classification was raised by $12 \%$, $22 \%, 24 \%, 29 \%$, and $53 \%$, respectively. Considering that this difference is not significant for this research, the data available for 37 years (1980-2016) were used.

Table 5 .

\subsection{Future climate data}

To project precipitation and temperature, the related data were downscaled using the CF method from the four CMIP6 models under two scenarios. The IPSL-CM6A-LR model was chosen with the least NRMSE and MBE and the highest NS for temperature and precipitation, respectively, to produce future climatic data (Table 6). Figure 4 demonstrates a specific trend in the monthly temperature variations compared to precipitation. The largest increase in temperature occurred in November $\left(1.76^{\circ} \mathrm{C}\right)$ and April $\left(2.32^{\circ} \mathrm{C}\right)$ under the SSP1-2.6 and SSP58.5 scenarios compared with the historical period. Furthermore, the highest increase and decrease in precipitation were seen in January (1.24) and April (0.85) under SSP5-8.5 compared to the historical period.

Table 6.

Figure 4. 


\subsection{Investigation of drought characteristics based on MSDI in historical and future periods}

Drought events are mostly characterized using drought duration (the length of the dry period), drought severity (summation of index values during the dry period), drought average severity (average of index values during the dry period), and drought intensity (minimum index value during the dry period) (Afshar et al., 2020). Among these characteristics, severity and duration were selected in the current research. After the calculation of MSDI, drought severity and duration were extracted based on a threshold level of -1 according to Run Theory in historical and future periods (Figure 5).

\section{Figure 5 .}

According to these figures, drought characteristics of the most severe event with three time scales $(6,9$, and 12) were obtained for the historical and future periods (Table 7). By increasing the time scale, the frequency of the dry period decreases, which is accompanied by an increase in the severity and duration of drought. As can be observed, in the historical period, the most severe drought had a severity, duration, and number, ranging from -25.56 to $-47.83,10$ to 24 months, and 11 to 6 . The highest drought severity generated by the SSP1-2.6 and SSP5-8.5 scenarios was increased from -28.3 to -54.4 and -30.31 to -60.3 , respectively. The drought derived from MSDI under the SSP5-8.5 scenario had a higher severity than those under other scenarios.

Tale 7.

Strong linear dependence based on Kendall and Spearman Coefficient $(\tau, \rho>0.8)$ was obtained between the severity (S) and duration (D) of the drought in the historical and future periods under two scenarios in all time scales (correlations are statistically significant at $95 \%$ confidence level). Based on these coefficients and comparison with the range of Kendall's $\tau$, all of the copula functions were selected for the next stage. The univariate CDFs of drought 
characteristics are necessary to fit the copula functions. Hence, a total of 11 univariate distribution functions were fitted to drought severity and duration to determine the marginal distribution functions, and the parameters of these functions were estimated using the maximum likelihood method. The Log-Normal, Log-Logistic, Normal, Logistic, and GEV functions were selected as the best fit for drought duration, and the Weibull, Normal, Log-Logistic, LogNormal, and GEV functions as the best fit for drought severity based on statistical tests including Kolmogorov-Smirnov and evaluation criteria (NRMSE, NS, and K_S) for both periods (Table 8). As can be seen, the NRMSE and NS values are closer to 0 and 1 , respectively, which indicates a perfect fit for the data.

\section{Table 8.}

\subsection{Investigation of copula functions for drought severity and duration}

The parameters of the functions for MSDI were estimated based on IFM to fit the copula functions to drought severity and duration. The best copula function to investigate the joint behavior of the drought severity and duration in the historical period is Galambos (Table 9). The NRMSE and $S_{n}$ are close to 0 and NS close to 1, which indicates the good fit of copula function to the data. Moreover, the Clayton copula functions were determined under SSP1-2.6 and SSP58.5 since they had the lowest NRMSE and $S_{n}$ and the highest NS. 
Table 9.

After selecting the best copula function, the joint probabilities of drought severity and duration are obtained (For example, the probabilities for the 6-month time scale are presented in Figure 6). As shown in this figure, the probability of severe and long drought occurrence is higher than in the historical period under the two scenarios. Moreover, the probability of severe drought is more in SSP5-8.5 than in the SSP1-2.6 scenario.

Figure 6.

\subsection{Return periods}

The bivariate drought return period was calculated using the Galambos and Clayton copulas in the historical and future periods, which can show the joint behavior of the drought characteristics. For instance, the average time interval between the drought events based on MSDI6 in the historical period, SSP1-2.6, and SSP5-8.5 are 8.1, 7.2, and 6.8 months. Figures 7 shows the joint return period of severity and duration of drought based on MSDI6 in the historical and future periods (SSP1-2.6 and SSP5-8.5) in both $T_{D S}$ (and) and $T_{D S}$ (or). As can be seen, the maximum return period $T_{D S}$ (or) is less than $T_{D S}$ (and).

As a consequence in $T_{D S}$ (and), the maximum drought return period in the historical period is 250 years, while in the future period, under the SSP1-2.6 and SSP5-8.5 scenarios, it will be 350 and 400 years, respectively. This indicates that a drought event will occur with a longer return period in the future under two scenarios. For example, a drought event with a return period of 150 years has a severity ranging from 18 to 20 and a duration ranging from 8 to 9 months, while in the future period under the SSP1-2.6, it has a severity ranging from 23 to 25 and a duration of more than 11 months and under SSP5-8.5 scenarios, it has a severity of more than 25 and a duration of 11 months. Overall, the droughts in the future would become more severe and longer. 
According to this Figure ( $T_{D S}($ or $)$ ), the maximum drought return period in the historical period is 160 years, while in the future period, it will be reduced to 60 and 60 years under the SSP1-2.6 and SSP5-8.5 scenarios, respectively. This demonstrates that droughts in the future would become more frequent and more severe. For instance, a drought event with a return period of 10 years has a severity of 20 and a duration of 10 months, while in the future period under SSP12.6, it has a severity of 25 and a duration of 11 and under SSP5-8.5 a severity of 28 and a duration of 11 months. In other words, the drought occurrence probability is higher in the future than in the historical period. Finally, the impact of climate change on univariate and joint return periods of droughts with different duration and average severity is presented in Table 10. As can be observed, the joint return period of mild drought (a return period of 5 years) does not change much within the historical and future periods $\left(T_{D S}\right.$ (and), $T_{D S}$ (or)) than that of extreme drought (a return period of 35 years).

Figure 7.

Table 10.

\section{Conclusion}

Climate change increases the odds of worsening drought conditions in many parts of Iran and the world in the decades ahead. The objective of this study was to investigate the impact of climate change on the probability of drought occurrence over Arak plain, Iran. To this end, a new index is proposed using the concept of Entropy Weighting and the SPEI (meteorological) and SSI (agricultural) indices. Future climate data were extracted using the IPSL-CM6A-LR model as the best model in this study under SSP1-2.6 and SSP5-8.5 scenarios. Using copula theory, the joint behavior of drought duration and severity was analyzed in terms of MSDI. The findings showed that by increasing the time scale, the frequency of the dry period decreases, 
which is accompanied by an increase in the severity and duration of droughts. The best fitted marginal distribution functions were found to be Log-Normal, Log-Logistic, Normal, Logistic, and GEV functions for duration and Weibull, Normal, Log-Logistic, Log-Normal, and GEV functions for severity over the study area. Based on the evaluation criteria, Galambos and Clayton functions were selected to drive copula-based joint distribution functions. The six-month time scale was selected for bivariate analysis because of the higher frequency of droughts in this scale compared to other time scales (9 and 12). The results show that more severe and longer droughts will occur in the future, particularly based on the SSP5-8.5 scenario. In other words, the drought occurrence probability is more in the future than in the historical period. When both the severity and duration exceeded a defined value $\left(T_{D S}\right.$ (and)), the joint return period of drought was longer than when either variable (i.e. severity or duration) exceeded separately a defined value ( $T_{D S}($ or)). Moreover, the frequency of mild drought remained the same under climate change, while the frequency of extreme drought was reduced. These results imply that the future drought conditions, especially in countries such as Iran, which have an arid and semi-arid climate and are affected by climate change, will be worse and these countries are especially vulnerable, and so adaptive solutions must be developed for the optimal management of water resources.

\section{Declarations}

Author Contribution: M.M.: Conceptualization, Methodology, Technical Investigation, Writing, Reviewing and Editing, Visualization, Supervision; A.Sh.: Software, Data Curation, Validation, Editing; K.N.: writing, original draft preparation.

Funding: The authors did not receive support from any organization for the submitted research.

Conflict of interest: The authors declare no conflict of interest. 
Availability of data and material: Available on request.

Code availability: The software used in this research will be available (by the corresponding author), upon reasonable request.

Ethics approval: Not applicable, because this article does not contain any studies with human or animal subjects.

Consent to participate: The research data were not prepared through a questionnaire.

Consent for publication: There is no conflict of interest regarding the publication of this article.

Funding: The authors did not receive support from any organization for the submitted research.

\section{References}

Afshar, M. H., Şorman, A. Ü., Tosunoğlu, F., Bulut, B., Yilmaz, M. T. and Danandeh Mehr, A. (2020). Climate change impact assessment on mild and extreme drought events using copulas over Ankara, Turkey. Theoretical and Applied Climatology, 141, 1045-1055.

Ahmad, M. I., Sinclair, C. D. and Werritty, A. (1988). Log-logistic flood frequency analysis. Journal of Hydrology, 98(3-4), 205-224

AghaKouchak, A. (2014). A baseline probabilistic drought forecasting framework using standardized soil moisture index: application to the 2012 United States drought. Hydrology and Earth System Sciences, 18(7), 2485-2492.

AghaKouchak, A., Farahmand, A., Melton, F. S., Teixeira, J., Anderson, M. C., Wardlow, B. D. and Hain, C. R. (2015). Remote sensing of drought: Progress, challenges and opportunities. Reviews of Geophysics, 53(2), 452-480. 
Amin, M. T., Mahmoud, S. H. and Alazba, A. A. (2016). Observations, projections and impacts of climate change on water resources in Arabian Peninsula: current and future scenarios. Environmental Earth Sciences, 75(10), 864.

Barker, L. J., Hannaford, J., Chiverton, A. and Svensson, C. (2016). From meteorological to hydrological drought using standardised indicators. Hydrology and Earth System Sciences, 20(6), 2483-2505.

Bazrafshan, O., Zamani, H., \& Shekari, M. (2020). A copula-based index for drought analysis in arid and semi-arid regions of Iran. Natural Resource Modeling, 33(1), e12237.

Cammalleri, C., Micale, F.and Vogt, J. (2016). A novel soil moisture-based drought severity index (DSI) combining water deficit magnitude and frequency. Hydrological Processes, 30(2), 289-301.

Carrão, H., Russo, S., Sepulcre-Canto, G. and Barbosa, P. (2016). An empirical standardized soil moisture index for agricultural drought assessment from remotely sensed data. International journal of applied earth observation and geoinformation, 48, 74-84.

Danandeh Mehr, A. and Kahya, E. (2017). Climate change impacts on catchment-scale extreme rainfall variability: case study of Rize Province, Turkey. Journal of Hydrologic Engineering, 22(3), 05016037.

Das, J., Jha, S., \& Goyal, M. K. (2020). Non-stationary and copula-based approach to assess the drought characteristics encompassing climate indices over the Himalayan states in India. Journal of Hydrology, 580, 124356.

Deo, R. C. and Şahin, M. (2015). Application of the artificial neural network model for prediction of monthly standardized precipitation and evapotranspiration index using 
hydrometeorological parameters and climate indices in eastern Australia. Atmospheric research, $161,65-81$.

Deo, R. C. and Şahin, M. (2015). Application of the extreme learning machine algorithm for the prediction of monthly Effective Drought Index in eastern Australia. Atmospheric Research, 153, 512-525.

Deo, R. C., Kisi, O. and Singh, V. P. (2017). Drought forecasting in eastern Australia using multivariate adaptive regression spline, least square support vector machine and M5Tree model. Atmospheric Research, 184, 149-175.

Dorigo, W. A., Gruber, A., De Jeu, R. A. M., Wagner, W., Stacke, T., Loew, A., ... \& Kidd, R. (2015). Evaluation of the ESA CCI soil moisture product using ground-based observations.Remote Sensing of Environment, 162, 380-395.

Dubrovsky, M., Svoboda, M. D., Trnka, M., Hayes, M. J., Wilhite, D. A., Zalud, Z.,Hlavinka, P.(2008). Application of relative drought indices in assessing climate-change impacts on drought conditions in Czechia. Theoretical and Applied Climatology, 96, 155-171.

Eyring,V., Bony, S., Meehl, G.A., Senior, C.A., Stevens, B., Stouffer, R.J. and Taylor, K.E. (2016). Overview of the Coupled Model Intercomparison Project Phase 6 (CMIP6) experimental design and organization, Geoscientific Model Development, 9, 1937-1958.

FAO, (2017). Drought characteristics and management in Central Asia and Turkey. Rome.

Gao, Z., Xu, N., Fu, C., Ning, J., Area, A.S. ( 2015). Evaluating drought monitoring methods using remote sensing : a dynamic correlation analysis between heat fluxes and land cover patterns. IEEE Journal of Selected Topics in Applied Earth Observations and Remote Sensing, 8 (1), 298-303. 
Hameed, M., Ahmadalipour, A. and Moradkhani, H. (2018). Apprehensive drought characteristics over Iraq: results of a multidecadal spatiotemporal assessment. Geosciences, 8(2), 58.

Hameed, M., Ahmadalipour, A., \& Moradkhani, H. (2020). Drought and food security in the middle east: An analytical framework. Agricultural and Forest Meteorology, 281, 107816.

Hang, Q, Xiao, M. and Singh, V.P. (2015). Uncertainty evaluation of copula analysis of hydrological droughts in theEast River basin, China. Global and Planetary Change, 129, 1-9.

Hao, Z. and AghaKouchak, A. (2013). Multivariate standardized drought index: a parametric multi-index model. Advances in Water Resources, 57, 12-18.

Huang, S., Huang, Q., Leng, G. and Liu, S. (2016). A nonparametric multivariate standardized drought index for characterizing socioeconomic drought: A case study in the Heihe River Basin. Journal of Hydrology, 542, 875-883.

IPCC-TGCIA, (2007). General guidelines on the use of scenario data for climateimate impact and adaptation assessment, K. Alfsen, E. Barrow, B. Bass, X. Dai, P. Desanker, S.R. Gaffin, F. Giorgi, M. Hulme, M. Lal, L.J. Mata, L.O. Mearns, J.F.B. Mitchell, T. Morita, R. Moss, D. Murdiyarso, J.D. Pabon-Caicedo, J. Palutikof, M.L. Parry, C. Rosenzweig, B. Seguin, R.J. Scholes, P.H. Whetton, Task Group on Data and Scenario Support for Impact and Climate Assessment

Joe, H. (1997). Multivariate models and multivariate dependence concepts. CRC Press.

Khajeh, S., Paimozd, S. and Moghaddasi, M. (2017). Assessing the impact of climate changes on hydrological drought based on reservoir performance indices (case study: ZayandehRud River basin, Iran). Water Resources Management, 31(9), 2595-2610. 
Kendall, D.R. and Dracup, J.A. (1992). On the generation of drought events using an alternating renewal-reward model. Stochastic Hydrology and Hydraulics, 6(1), 55-68.

Liu, Y. Y., Dorigo, W. A., Parinussa, R. M., De Jeu, R. A. M., Wagner, W., McCabe, M. F., ... \& Van Dijk, A. I. J. M. (2012). Trend-preserving blending of passive and active microwave soil moisture retrievals.Remote Sensing of Environment,123, 280-297.14.

Liu, Y. Y., Parinussa, R. M., Dorigo, W. A., De Jeu, R. A. M., Wagner, W., Van Dijk, A. I. J. M., ... \& Evans, J. P. (2011). Developing an improved soil moisture dataset by blending passive andactive microwave satellite-based retrievals.Hydrology and Earth System Sciences,15(2), 425436

Ma, M.W.; Ren, L.L.; Song, S.B.; Song, J. L.; Jiang, S.H. (2013). Goodness-of-fit tests for multi-dimensional copulas: expanding application to historical drought data. Water Sci. Engineering, 6, 18-30

Mathbout, S., Lopez-Bustins, J. A., Martin-Vide, J., Bech, J. and Rodrigo, F. S. 2018. Spatial and temporal analysis of drought variability at several time scales in Syria during 19612012. Atmospheric Research, 200, 153-168.

Mathier, L., Perreault, L., Bobe, B. and Ashkar, F. (1992). The use of geometric and gammarelated distributions for frequency analysis of water deficit. Stochastic Hydrology and Hydraulics, 6(4), 239-254.

McKee, T.B., Doesken, N.J. and Kleist, J. (1993). The relationship of drought frequency and duration to time scales. American Meteorological Society. 8th Conference on Applied Climatology, 17-22 Janvier, Anaheim, California, 179-184. Boston, MA: American.

McKee, T.B., Doesken, N.J. and Kleist J. (1995). Drought monitoring with multiple time scales. In: 482 9th Conference on Applied Climatology, Am Meteor Soc 233-236. 
Mesbahzadeh, T., Mirakbari, M., Mohseni Saravi, M., Soleimani Sardoo, F., \& Miglietta, M. M. (2020). Meteorological drought analysis using copula theory and drought indicators under climate change scenarios (RCP). Meteorological Applications, 27(1), e1856.

Mirabbasi, R., Fakheri-Fard, A. and Dinpashoh, Y. (2012). Bivariate drought frequency analysis using the copula method. Theoretical and applied climatology, 108(1), 191-206.

Mishra, A. K. and Singh, V. P. (2010). A review of drought concepts. Journal of hydrology, 391(1-2), 202-216.

Mitchell, T. D., \& Jones, P. D. (2005). An improved method of constructing a database of monthly climate observations and associated high-resolution grids. International Journal of Climatology: A Journal of the Royal Meteorological Society, 25(6), 693-712.

Mohammed, R. and Scholz, M. (2017). The reconnaissance drought index: a method for detecting regional arid climatic variability and potential drought risk. Journal of Arid Environments, 144, 181-191.

Nelsen, R. B. (2006). An Introduction to Copulas. Springer, New York. MR2197664.

New, M., Hulme, M. and Jones, PD. (1999). Representing twentieth-centuryspace-time climate variability.Part I: development of a 1961-90 mean monthly terrestrial climatology. Journal of Climate, 12: 829 - 856.

Rahmani Kam, A. (2015). Soil moisture routing using remote sensing products, Mater's thesis, University of Shahrood.

Sajeev, A., Deb Barma, S., Mahesha, A., \& Shiau, J. T. (2021). Bivariate drought characterization of two contrasting climatic regions in India using copula. Journal of Irrigation and Drainage Engineering, 147(3), 05020005. 
Scanlon, B. R., Ruddell, B. L., Reed, P. M., Hook, R. I., Zheng, C., Tidwell, V. C. and Siebert, S. (2017). The food-energy-water nexus: Transforming science for society. Water Resources Research, 53(5), 3550-3556.

Sheffield, J. and Wood, E.F. (2008). Projected changes in drought occurrence under future global warming from multi-model, multi-scenario. IPCC AR4 simulations. Climate dynamics, 31, 79-105.

Shiau, J. T. (2006). Fitting drought duration and severity with two-dimensional copulas. Water Resources Management, 20(5), 795-815.

Sklar, M. (1959). Fonctions de repartition an dimensions etleurs marges. Publ. inst. statist. univ. Paris, 8, 229-231.

Solomon, S., Qin, D., Manning, M., Marquis, M., Averyt, K., Tignor, M.M.B., Miller, H.L., Jr. and Chen, Z. (Eds.). (2007) Climate Change 2007: The Physical Science Basis. Contribution of Working Group I to the Fourth Assessment Report of the Intergovernmental Panel on Climate Change. Cambridge: Cambridge University Press, p. 996.

Svoboda, M., \& Fuchs, B. (2016). Handbook of drought indicators and indices.

Thilakarathne, M. and Sridhar, V. (2017). Characterization of future drought conditions in the Lower Mekong River Basin. Weather and Climate Extremes, 17, 47-58.

Thornthwaite, C.W. (1948). An approach toward a rational classification of climate Geogr Rev 50838 (1948), pp. 55-94

Tirado, M. C., Clarke, R., Jaykus, L. A., McQuatters-Gollop, A. and Frank, J. M. (2010). Climate change and food safety: A review. Food Research International, 43(7), 1745-1765. 
Tsakiris, G., Pangalou, D. and Vangelis, H. (2007). Regional drought assessment based on the Reconnaissance Drought Index (RDI). Water resources management, 21(5), 821-833.

Van Loon, A. F., Ploum, S. W., Parajka, J., Fleig, A. K., Garnier, E., Laaha, G. and Van Lanen, H. A. (2014). Hydrological drought typology: temperature-related drought types and associated societal impacts. Hydrology \& Earth System Sciences Discussions, 11(9).

Van Loon, A. F. and Laaha, G. (2015). Hydrological drought severity explained by climate and catchment characteristics. Journal of hydrology, 526, 3-14.

Van Loon, A. F. (2015). Hydrological drought explained. Wiley Interdisciplinary Reviews: Water, 2(4), 359-392.

Vicente-Serrano, S.M., Begueria,, S. and Lopez-Moreno, J. I. ( 2010a). A Multi-scalar drought index sensitive to global warming: The Standardized Precipitation Evapotranspiration Index SPEI. Journal of climate, 23, 1696-1718.

Vicente-Serrano, S.M., Beguería, S., Lorenzo-Lacruz, J., Camarero, J.J., López-Moreno, J.I., Azorin-Molina, C., Revuelto, J., Morán-Tejeda, E. and Sánchez-Lorenzo, A. (2012) Performance of drought indices for ecological, agricultural and hydrological applications. Earth Interactions, $16,1-27$.

Wagner, W., Dorigo, W., de Jeu, R., Fernandez, D., Benveniste, J., Haas, E., \& Ertl, M. (2012). Fusion of active and passive microwave observations to create an essential climate variable data record on soil moisture. InXXII ISPRS Congress, Melbourne, Australia,315-321

Wilhite, D. A. and Glantz, M. H. (1985). Understanding: the drought phenomenon: the role of definitions. Water international, 10(3), 111-120. 
Wilhite, D. A. Sivakumar, M. V. and Pulwarty, R. (2014). Managing drought risk in a changing climate: The role of national drought policy. Weather and Climate Extremes, 3, 4-13.

Zhang, L., Liu, Y., Ren, L., Jiang, S., Yang, X., Yuan, F., ... \& Wei, L. (2019). Drought Monitoring and Evaluation by ESA CCI Soil Moisture Products Over the Yellow River Basin. IEEE Journal of Selected Topics in Applied Earth Observations and Remote Sensing, 12(9), 3376-3386.

Zhang, L., Wang, Y., Chen, Y., Bai, Y. and Zhang, Q. (2020). Drought risk assessment in Central Asia using a probabilistic copula function approach. Water, 12(2), 421.

Yan, H., Moradkhani, H. and Zarekarizi, M. (2017). A probabilistic drought forecasting framework: A combined dynamical and statistical approach. Journal of Hydrology, 548, 291304. 
Table 1. Assessing the performance of CRU dataset over the case study

\begin{tabular}{cccc}
\hline Variable & $\mathrm{R}^{2}$ & NRMSE & MBE \\
\hline Precipitation & 0.89 & 0.4 & 0.07 \\
\hline Temprature & 0.98 & 0.12 & -0.04 \\
\hline
\end{tabular}

Table 2. Information from four CMIP6 climate models used in this study

\begin{tabular}{ccc}
\hline Model & Source & $\begin{array}{c}\text { Spatial } \\
\text { resolution } \\
(\text { lat } \times \text { lon })\end{array}$ \\
\hline BCC-CSM2-MR & Beijing Climate Center, China & $1.125^{\circ} \times 1.125^{\circ}$ \\
\hline CanESM5 & Canadian Center for Climate Modeling and Analysis, \\
Canada & $2.8125^{\circ} \times 2.8125^{\circ}$ \\
\hline IPSL-CM6A-LR & Institute Pierre-Simon Laplace, France & $1.26^{\circ} \times 2.5^{\circ}$ \\
\hline ACCESS-CM2 & The Centre for Australian Weather and Climate Research, \\
\end{tabular}


Table 3. Classifications of wet and dry conditions using MSDI

\begin{tabular}{ll}
\hline \multicolumn{1}{c}{ Drought Classification } & MSDI \\
\hline Extreme Wet & More than 2 \\
\hline Severe Wet & 1.5 up to 2 \\
\hline Moderate Wet & 1 up to 1.5 \\
\hline Normal & -1 up to 1 \\
\hline Moderate dry & -1 up to -1.5 \\
\hline Severe dry & -1.5 up to -2 \\
\hline Extreme dry & Less than -2 \\
\hline
\end{tabular}

Table 4. Copula functions (Mirabbasi et al., 2012)

\begin{tabular}{lcc}
\hline Copula function & $\mathbf{C}(\mathbf{U}, \mathbf{V})$ & Paramspace \\
\hline Clayton & $\left(u^{-\infty}+v^{-\infty}-1\right)^{\frac{-1}{\theta}}$ & $\boldsymbol{\theta} \geq \mathbf{0}$ \\
\hline Frank & $\frac{-1}{\theta} \ln \left[1+\frac{\left(e^{-\theta u}-1\right)\left(e^{-\theta v}-1\right)}{e^{-\theta}-1}\right]$ & $\boldsymbol{\theta} \neq \mathbf{0}$ \\
\hline Galambos & $u v \exp \left[\left((-\ln u)^{-\theta}+(-\ln v)^{-\theta}\right)^{\frac{-1}{\theta}}\right]$ & $\boldsymbol{\theta} \geq \mathbf{0}$ \\
\hline Gumbel- & $\exp \left[-\left[(-\ln u)^{\theta}+(-\ln v)^{\theta}\right]^{\frac{1}{\theta}}\right]$ & $\boldsymbol{\theta} \geq \mathbf{1}$ \\
\hline Plackett & $\frac{1}{2} \frac{1}{\theta-1}\left[1+(\theta-1)(u+v)-\left[(1+(\theta-1)(u+v))^{2}-4 \theta(\theta-1) u v\right]^{\frac{1}{2}}\right.$ & $\boldsymbol{\theta} \geq \mathbf{0}$ \\
\hline
\end{tabular}


Table 5. Frequency of match and non-match drought classification for the overall region using different record periods (37\& 100 years) in different time scales $(1,3,6,9,12)$

\begin{tabular}{|c|c|c|c|c|c|c|c|c|}
\hline \multicolumn{9}{|c|}{ SPEI 1 (37-Year) } \\
\hline \multirow{5}{*}{$\begin{array}{c}\text { SPEI } \\
(100-Y e a r)\end{array}$} & & Extreme dry & Severe dry & Moderate dry & Normal & Moderate Wet & Severe Wet & Extreme Wet \\
\hline & Extreme dry & 4 & 6 & 1 & 0 & 0 & 0 & 0 \\
\hline & Moderate dry & 0 & 0 & 33 & 18 & 0 & 0 & 0 \\
\hline & Normal & 0 & 0 & 5 & 265 & 15 & 1 & 0 \\
\hline & Extreme Wet & 0 & 0 & 0 & 0 & 0 & 1 & 4 \\
\hline \multicolumn{9}{|c|}{ SPEI 3 (37- Year) } \\
\hline \multirow{4}{*}{$\begin{array}{c}\text { SPEI } \\
(100-Y e a r)\end{array}$} & & Extreme dry & Severe dry & Moderate dry & Normal & Moderate Wet & Severe Wet & Extreme Wet \\
\hline & Extreme dry & 5 & 8 & 0 & 0 & 0 & 0 & 0 \\
\hline & Severe Wet & 0 & 0 & 0 & 0 & 4 & 11 & 5 \\
\hline & Extreme Wet & 0 & 0 & 0 & 0 & 0 & 2 & 4 \\
\hline \multicolumn{9}{|c|}{ SPEI 6 (37- Year) } \\
\hline \multirow{6}{*}{$\begin{array}{c}\text { SPEI } \\
(100-Y e a r)\end{array}$} & & Extreme dry & Severe dry & Moderate dry & Normal & Moderate Wet & Severe Wet & Extreme Wet \\
\hline & Extreme dry & 7 & 5 & 1 & 1 & 0 & 0 & 0 \\
\hline & Severe dry & 1 & 12 & 7 & 4 & 0 & 0 & 0 \\
\hline & Moderate dry & 0 & 3 & 25 & 26 & 0 & 0 & 0 \\
\hline & Normal & 0 & 2 & 5 & 263 & 17 & 3 & 1 \\
\hline & Moderate Wet & 0 & 0 & 0 & 7 & 14 & 7 & 1 \\
\hline \multicolumn{9}{|c|}{ SPEI 9 (37-Year) } \\
\hline \multirow{5}{*}{$\begin{array}{c}\text { SPEI } \\
(100-Y e a r)\end{array}$} & Moderate dry & 0 & 3 & 20 & 29 & 1 & 0 & 0 \\
\hline & Normal & 0 & 2 & 6 & 250 & 27 & 3 & 1 \\
\hline & Moderate Wet & 0 & 0 & 0 & 5 & 16 & 9 & 0 \\
\hline & Severe Wet & 0 & 0 & 0 & 2 & 1 & 10 & 5 \\
\hline & Extreme Wet & 0 & 0 & 0 & 0 & 0 & 0 & 2 \\
\hline \multicolumn{9}{|c|}{ SPEI 12 (37-Year) } \\
\hline \multirow{8}{*}{$\begin{array}{c}\text { SPEI } \\
(100-Y e a r)\end{array}$} & & Extreme dry & Severe dry & Moderate dry & Normal & Moderate Wet & Severe Wet & Extreme Wet \\
\hline & Extreme dry & 3 & 11 & 1 & 1 & 0 & 0 & 0 \\
\hline & Severe dry & 0 & 10 & 17 & 4 & 0 & 0 & 0 \\
\hline & Moderate dry & 0 & 2 & 24 & 34 & 1 & 0 & 0 \\
\hline & Normal & 0 & 3 & 5 & 232 & 23 & 4 & 1 \\
\hline & Moderate Wet & 0 & 0 & 1 & 5 & 15 & 19 & 0 \\
\hline & Severe Wet & 0 & 0 & 0 & 2 & 1 & 10 & 2 \\
\hline & Extreme Wet & 0 & 0 & 0 & 0 & 0 & 0 & 0 \\
\hline
\end{tabular}


Table 6. Results of evaluation criteria for the four CMIP6 models

\begin{tabular}{ccccc}
\hline \multirow{2}{*}{ Parameters } & \multicolumn{1}{c}{ Model } & NS & NRMSE & MBE \\
\hline \multirow{2}{*}{ Precipitation } & CanESM5 & -0.49 & 1.25 & -5.45 \\
\cline { 2 - 5 } & BCC-CSM2-MR & -1.43 & 1.60 & 7.79 \\
\cline { 2 - 5 } & ACCESS-CM2 & -0.55 & 1.28 & 5.14 \\
\hline \multirow{2}{*}{ Temperature } & CanESM5 & 0.66 & 0.40 & -1.57 \\
\cline { 2 - 5 } & BCC-CSM2-MR & 0.66 & 0.4 & 0.25 \\
\cline { 2 - 5 } & ACCESS-CM2 & 0.71 & 0.37 & -4.48 \\
\cline { 2 - 5 } & IPSL-CM6A-LR & 0.89 & 0.22 & -2.1 \\
\hline
\end{tabular}

Table 7. The number, highest severity, and duration (month) of drought events under the historical and future periods

\begin{tabular}{|c|c|c|c|c|c|c|c|c|c|}
\hline \multicolumn{4}{|c|}{ Historical } & \multicolumn{3}{|c|}{ SSP1-2.6 } & \multicolumn{3}{|c|}{ SSP5-8.5 } \\
\hline \multirow{2}{*}{ Index } & \multirow{2}{*}{ Number } & Duration & Severity & \multirow{2}{*}{ Number } & Duration & Severity & \multirow{2}{*}{ Number } & Duration & Severity \\
\hline & & $\operatorname{Max}$ & Max & & Max & Max & & Max & $\operatorname{Max}$ \\
\hline MSDI 6 & 11 & 10 & -25.56 & 8 & 10 & -28.53 & 8 & 10 & -30.31 \\
\hline MSDI 9 & 7 & 22 & -42.02 & 5 & 24 & -47.43 & 7 & 24 & -50.7 \\
\hline MSDI 12 & 6 & 24 & -47.83 & 6 & 24 & -54.4 & 6 & 24 & -60.3 \\
\hline
\end{tabular}


Table 8 . The results of evaluation criteria for the best marginal distribution function

\begin{tabular}{|c|c|c|c|c|c|c|c|c|c|}
\hline \multirow{2}{*}{ Index } & \multirow{2}{*}{ Period } & \multicolumn{4}{|c|}{ Duration } & \multicolumn{4}{|c|}{ Severity } \\
\hline & & NRMSE & NS & K_S & Distribution & NRMSE & NS & K_S & Distribution \\
\hline \multirow{3}{*}{ MSDI 6} & Historical & 9.14 & 0.90 & 0.19 & Normal & 7.09 & 0.94 & 0.16 & Weibull \\
\hline & SSP1-2.6 & 10.88 & 0.86 & 0.22 & Logistic & 9.07 & 0.91 & 0.20 & Log Logistic \\
\hline & SSP5-8.5 & 10.90 & 0.89 & 0.22 & Logistic & 9.09 & 0.92 & 0.21 & Log Logistic \\
\hline \multirow{3}{*}{ MSDI 9} & Historical & 10.74 & 0.87 & 0.19 & Log Logistic & 8.68 & 0.92 & 0.13 & Log logistic \\
\hline & SSP1-2.6 & 8.08 & 0.93 & 0.18 & Logistic & 9.62 & 0.90 & 0.19 & Logistic \\
\hline & SSP5-8.5 & 8.78 & 0.91 & 0.23 & Normal & 12.40 & 0.83 & 0.20 & Logistic \\
\hline \multirow{3}{*}{ MSDI 12} & Historical & 9.42 & 0.90 & 0.22 & Gev & 8.26 & 0.92 & 0.20 & Gev \\
\hline & SSP1-2.6 & 10.40 & 0.88 & 0.20 & Lognormal & 8.36 & 0.92 & 0.18 & Lognormal \\
\hline & SSP5-8.5 & 10.06 & 0.89 & 0.19 & Lognormal & 7.31 & 0.94 & 0.20 & Lognormal \\
\hline
\end{tabular}

Table 9. The best copula function and evaluation criteria in the historical and future periods

\begin{tabular}{cllll}
\hline \multicolumn{6}{c}{ Historical } \\
\hline Copula Function & $\mathbf{S}_{\mathbf{n}}$ & NRMSE & NS & $\boldsymbol{\theta}$ \\
\hline Galambos & 0.04 & 5.87 & 0.97 & 3.47 \\
\hline \multicolumn{5}{c}{ SSP1-2.6 } \\
\hline Clayton & 0.03 & 6.09 & 0.97 & 5.15 \\
\hline SSP5-8.5 \\
\hline Clayton & 0.03 & 6.01 & 0.98 & 5.33 \\
\hline
\end{tabular}


Table 10. Comparison of the impact of climate change on univariate and joint return periods of droughts with different duration and severity amounts.

\begin{tabular}{|c|c|c|c|c|c|}
\hline \multirow{2}{*}{$\begin{array}{l}\text { Univariate return } \\
\text { period (year) }\end{array}$} & \multicolumn{2}{|c|}{ Drought characteristics } & \multirow{2}{*}{ Periods } & \multicolumn{2}{|c|}{$\begin{array}{c}\text { Joint return period } \\
\text { (year) }\end{array}$} \\
\hline & Severity & Duration & & and & or \\
\hline & 17 & 9 & Historical & 50 & 37 \\
\hline \multirow[t]{3}{*}{5} & & & SSP1-2.6 & 56 & 25 \\
\hline & & & SSP5-8.5 & 55 & 25 \\
\hline & 19 & 10 & Historical & 102 & 72 \\
\hline \multirow[t]{3}{*}{10} & & & SSP1-2.6 & 167 & 43 \\
\hline & & & SSP5-8.5 & 164 & 43 \\
\hline & 22 & 11 & Historical & 206 & 144 \\
\hline \multirow[t]{3}{*}{20} & & & SSP1-2.6 & 558 & 78 \\
\hline & & & SSP5-8.5 & 546 & 78 \\
\hline & 25 & 13 & Historical & 343 & 240 \\
\hline \multirow[t]{2}{*}{35} & & & SSP1-2.6 & 1424 & 124 \\
\hline & & & SSP5-8.5 & 1391 & 124 \\
\hline
\end{tabular}




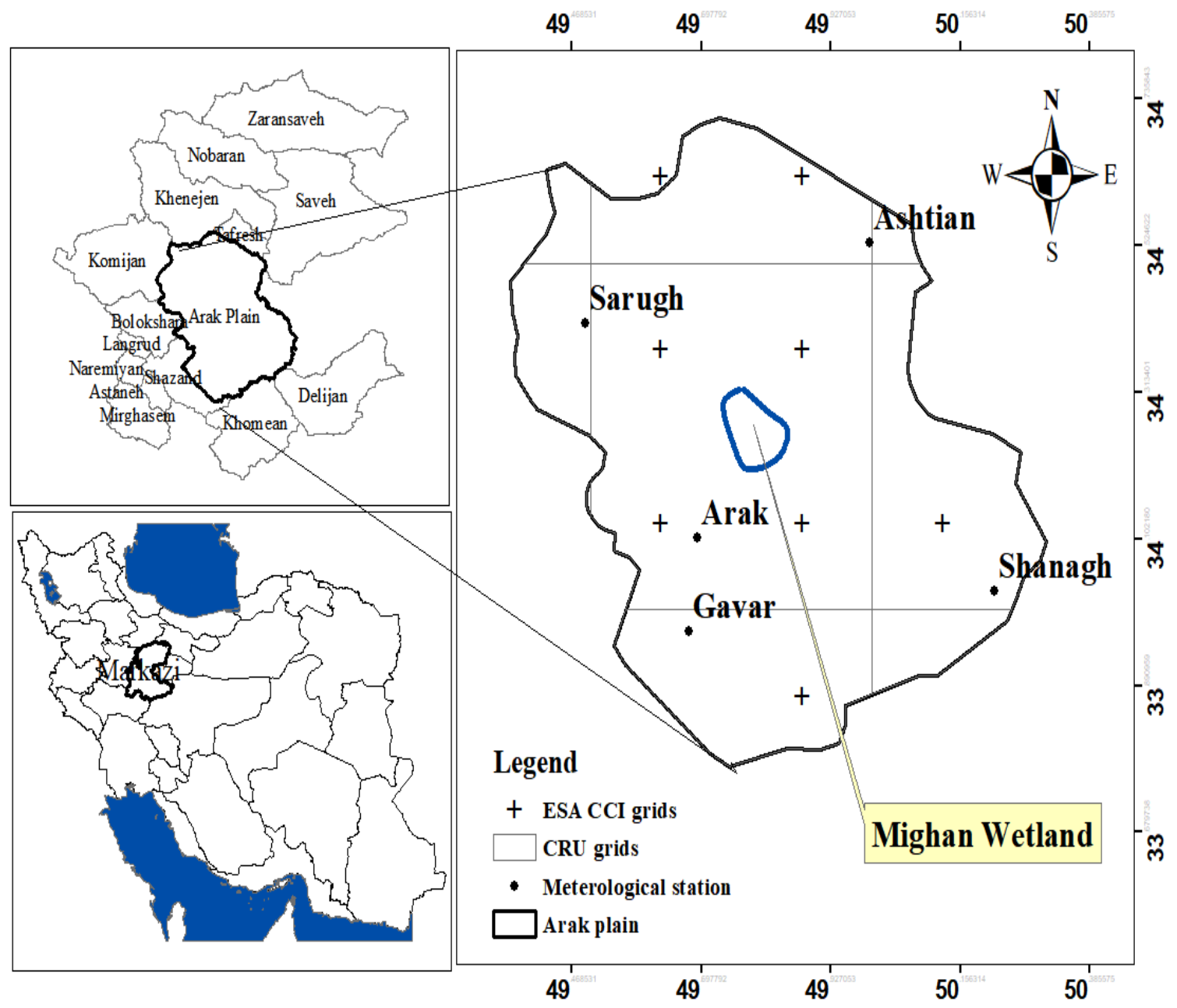

Figure 1. The Case Study 


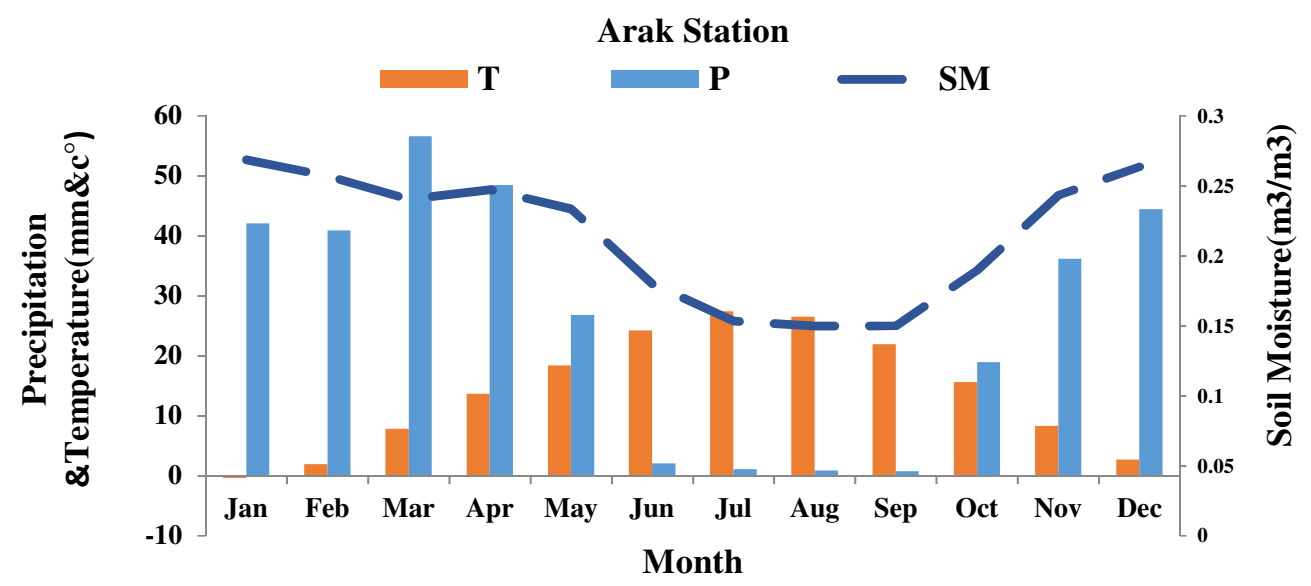

(a)

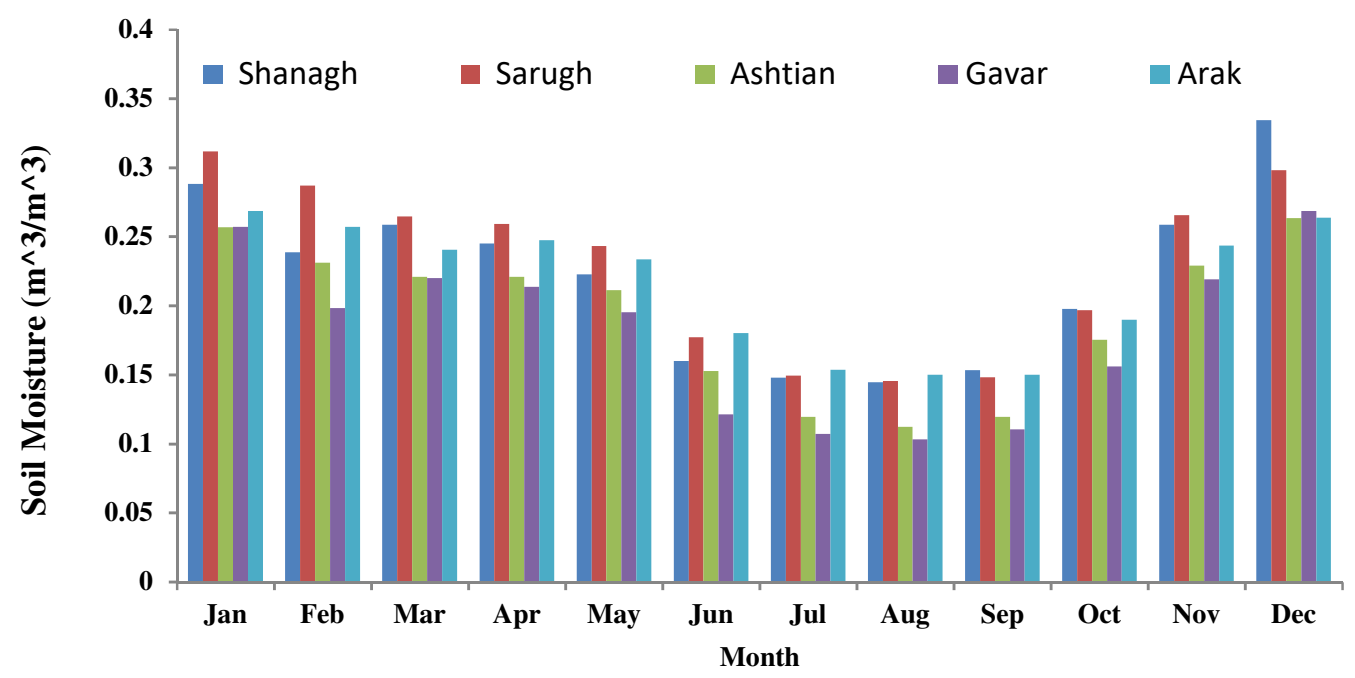

(b)

Figure 2. The changes of the monthly mean temperature, precipitation and soil moisture (a), the changes of the monthly mean soil moisture in the case study (b). 


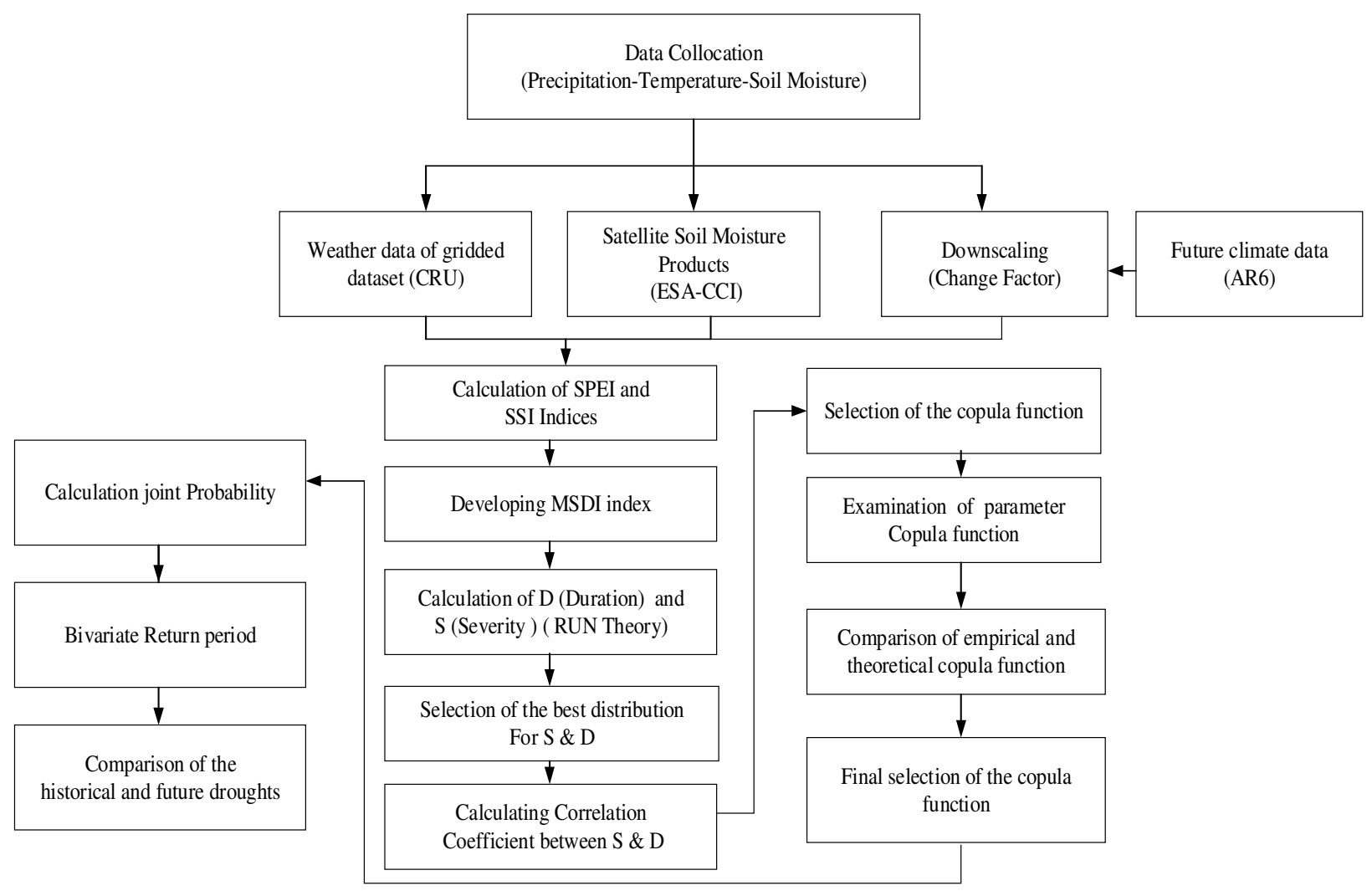

Figure 3. The research flowchart 

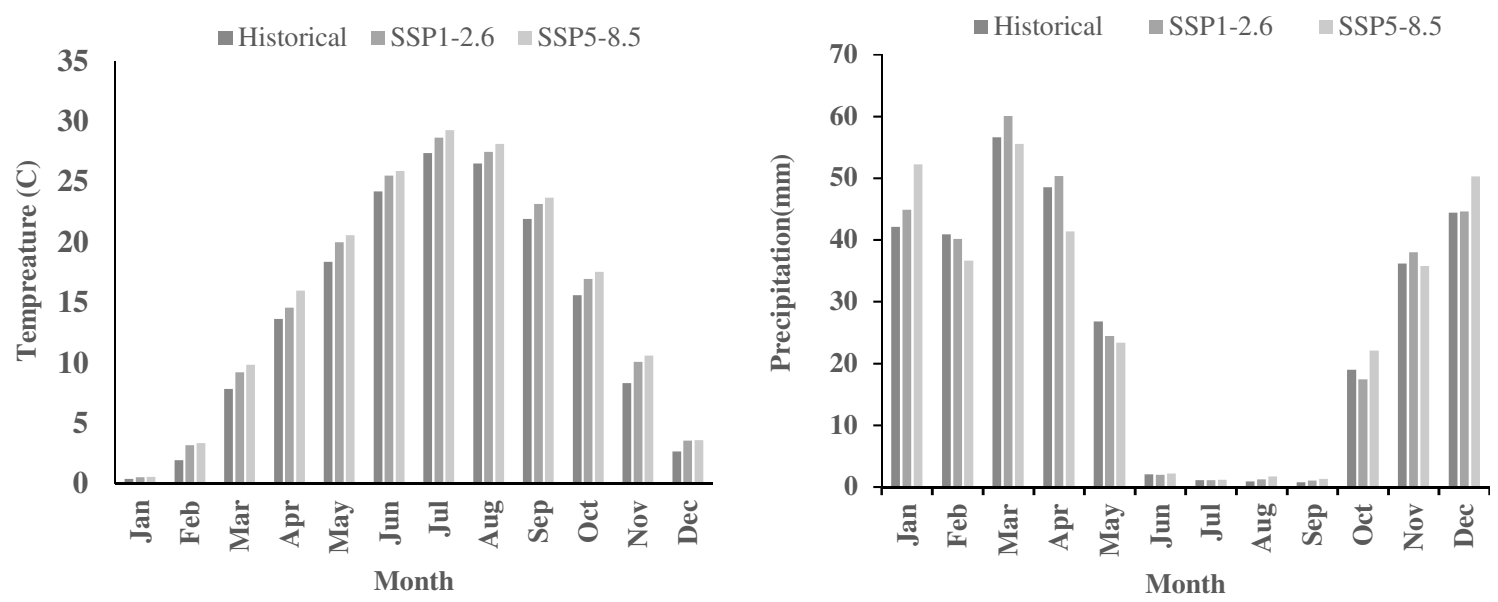

Figure 4. Changes of monthly mean temperature and precipitation compared to the historical period for SSP1-2.6 and SSP5-8.5 scenarios 


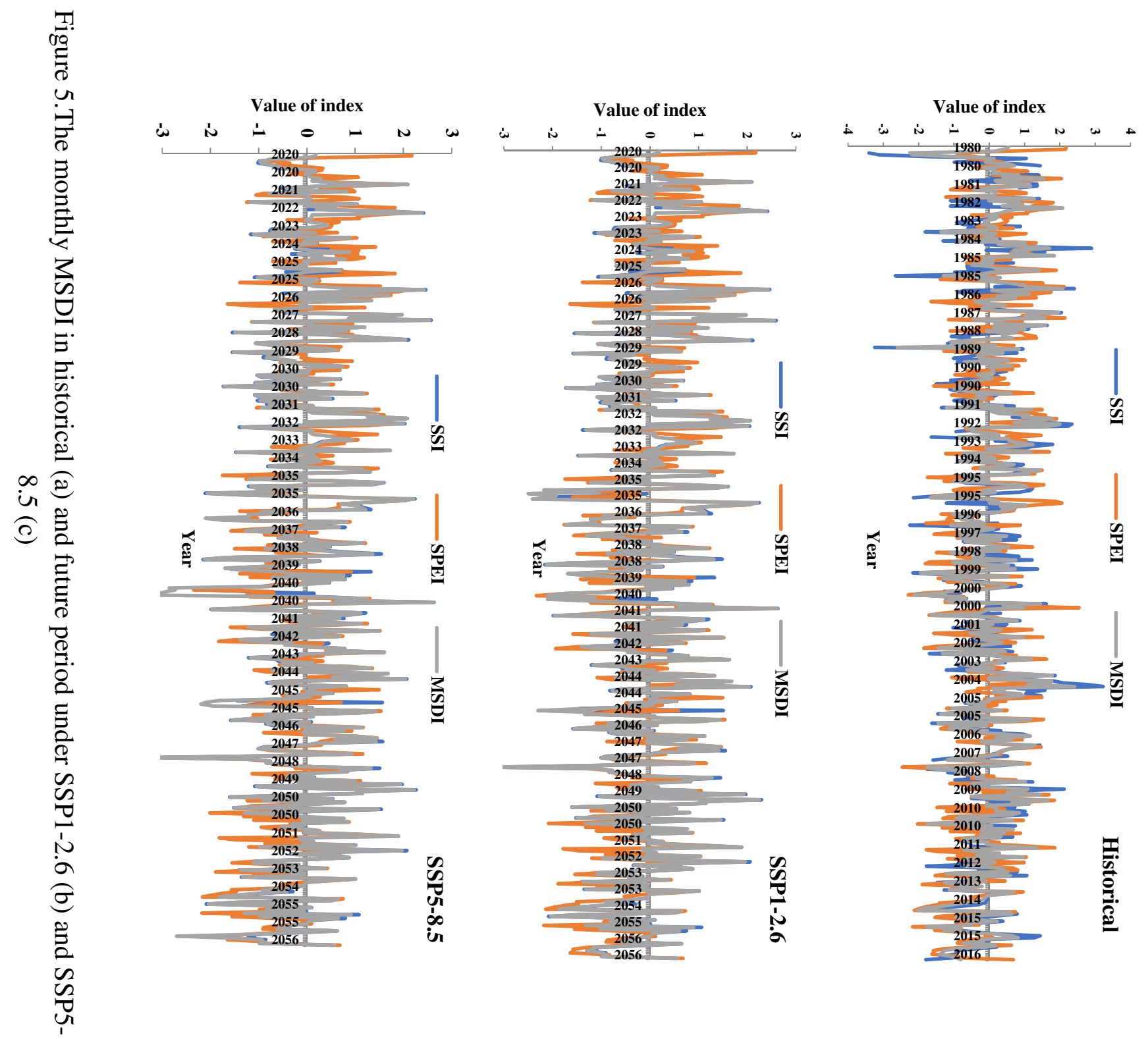




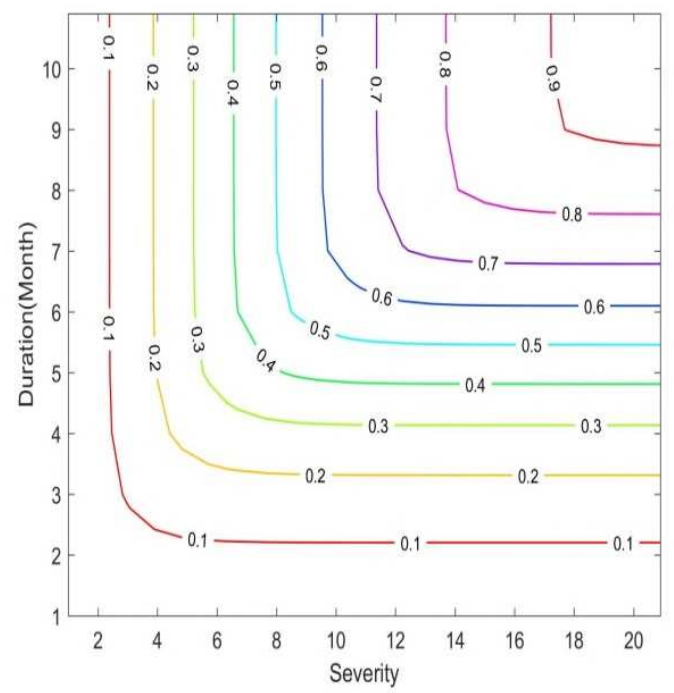

(a)

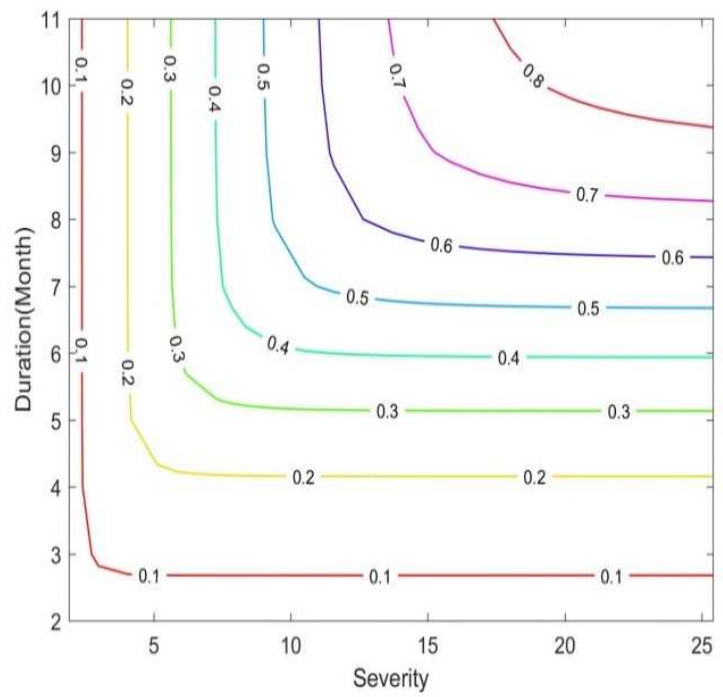

(b)

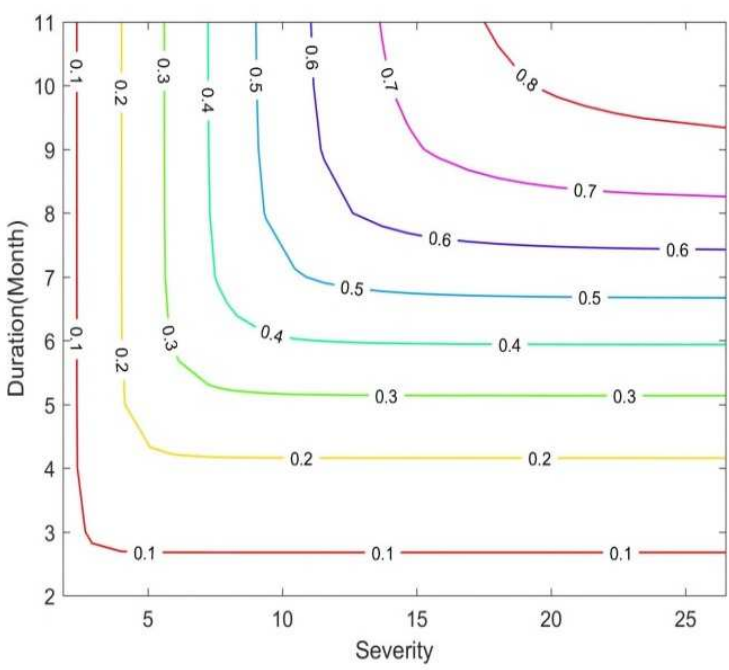

(c)

Figure 6. Joint probabilities of drought severity and duration based on MSDI6 for (a) historical, (b) SSP1-2.6, (c) SSP5-8.5 scenarios. 

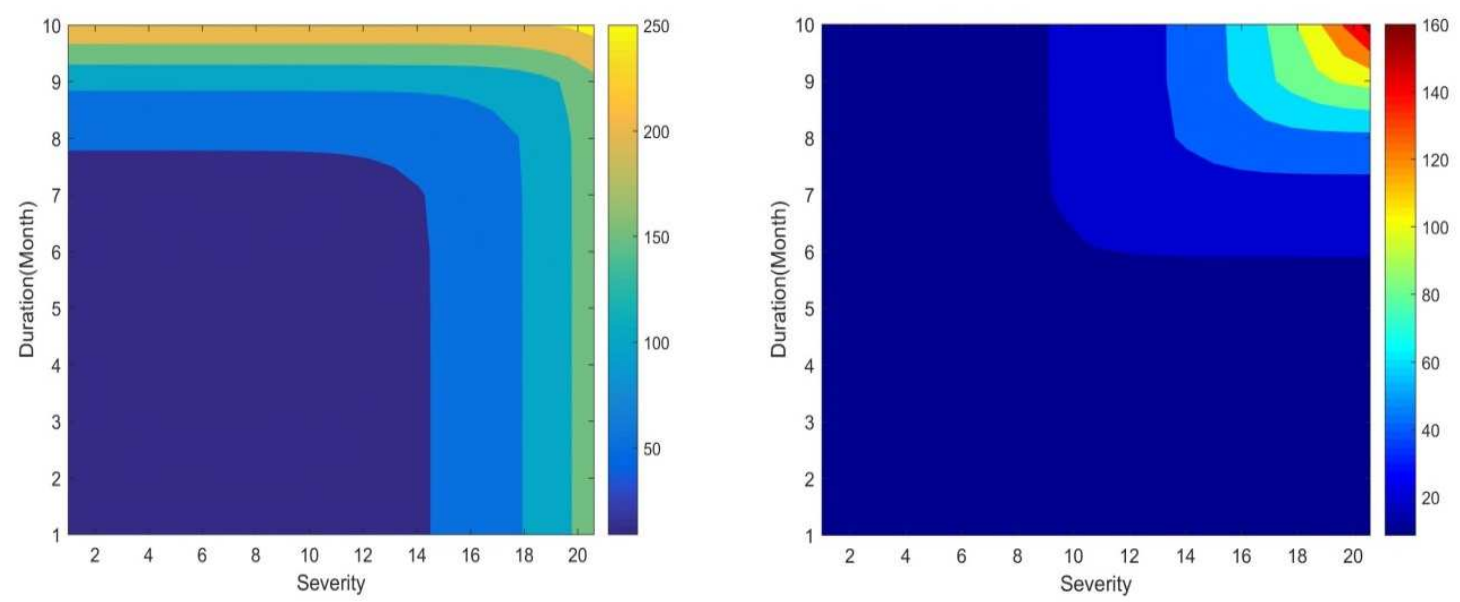

(a)
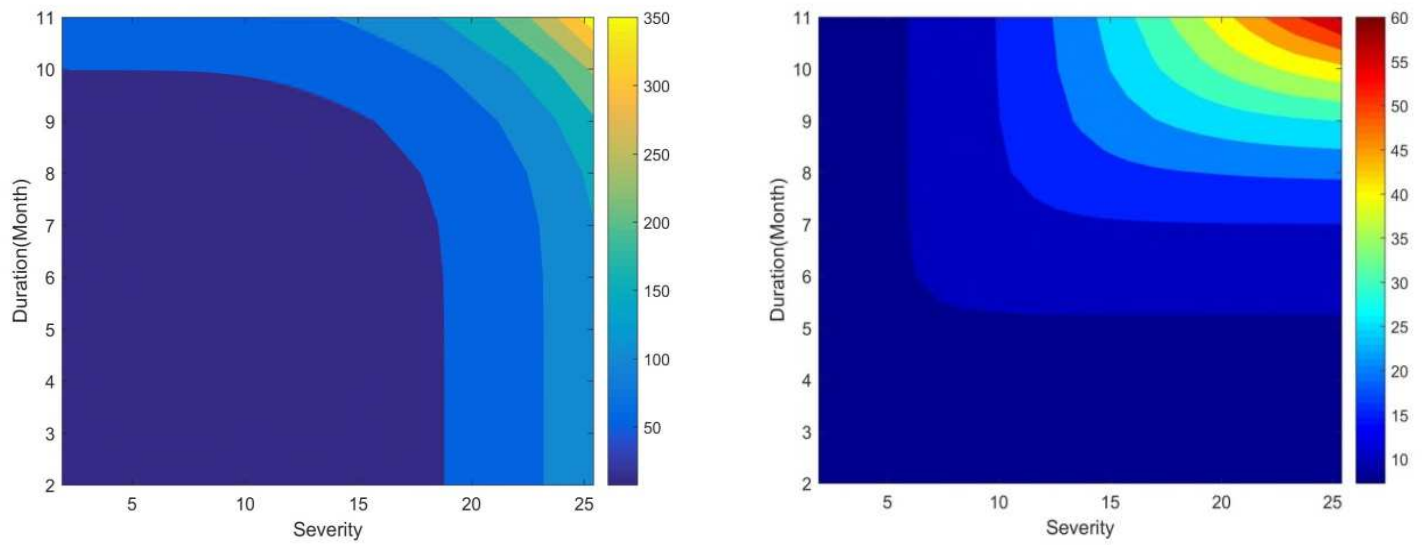

(b)
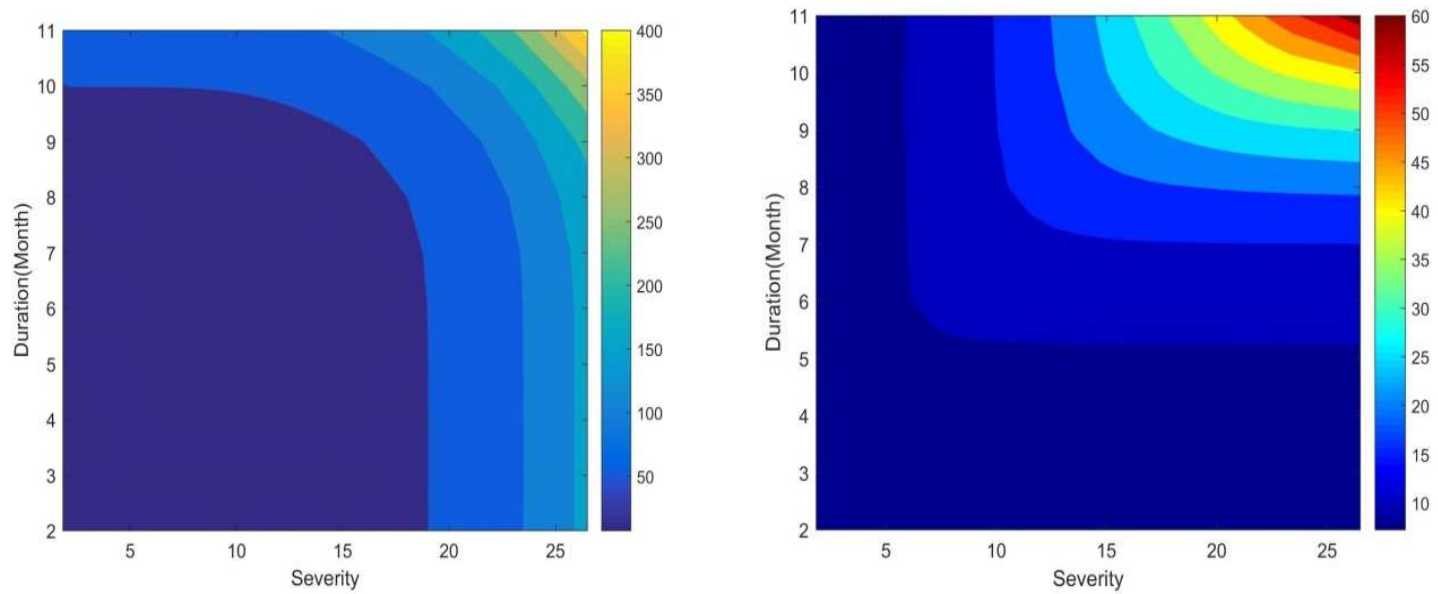

(c)

Figure 7. Joint return period of drought in the historical period (a) and under scenarios SSP1-2.6 (b) and SSP5-8.5(c) based on MSDI6 (and (left) and or (right)). 